\title{
Improve the Performance of an Electrical Distribution Systems using Common Techniques Take into Account Load Growth
}

\author{
${ }^{1}$ Ali Kadhem Hamzah and ${ }^{2}$ Mehdi F. Bonneya \\ ${ }^{1}$ Department of Electrical Engineering, Technical College, \\ ${ }^{2}$ Kut Technical Institute, Department of Electrical Techniques, Middle Technical University, \\ Baghdad, Iraq
}

\begin{abstract}
Load growth is considered in this research with a common techniques to solve the problem of voltage deviation and losses of active power assuming the worst working conditions of the distribution power system (load growth by $7 \%$ per year) for 5 years. Through, the ideal planning to identify ways and techniques that solve the problems mentioned above in the future. CYME package was tested for IEEE 69-buses standard system. This package demonstrated high efficiency in the improvement of the voltage of the system in addition to reducing the loss of power because it is a realistic program that takes into account the surrounding conditions of the system and this is confirmed by the figures and results obtained in this research.
\end{abstract}

Key words: CYME Software, distribution network, network reconfiguration, capacitors bank, load growth, demonstrated

\section{INTRODUCTION}

The goal of Distribution System (DS) planning and designing is to meet the annum load growth for the planning duration, system voltage enhancement, mitigate active power losses and improve the system performance. The system planning process is done by either planning to expand the current network taking into account the growth of loads or by building a new network.

The system planning process consists of two main stages. The first stage is the essential analysis of load flow which is used to known the behavior of existing distribution system. The second phase consists of load growth, optimization of network and (VAR) compensators (Kuzel et al., 2009). There ar many approaches used to cope with the growing demand for electric power and load growth. These methods are divided as for increasing the capacity a of system parts such as (feeders, transformers) or using alternative techniques to improve system performance such as Load Balancing (LB), Network Reconfiguration (NR), installation Bank of Capacitors (BC), New Conductors Installation (NCI) of feeder and re-sizing the feeder conductors.

In this resaerch two techniques have been executed to obtain on optimal planning for (DS), they are (NR) technique and $(\mathrm{BC})$ technique. Distribution system is the last stage of a power system cycle and this is where electrical energy is distributed to several types of consumers individually through several feeders and lateral branches (Badran et al., 2017). Most of this 2 feeders are radial type. Radial feeders have overall low cost and the task of maintenance them is not complicated (Ganesh, 2014). Each one of them has mixture of different kind of loads and these loads have several daily patterns which make the peak demand for each load type occurs at a varying period of time which makes feeders in the process of unbalance which means that heavily loaded feeders are prone to voltage drop problems and significant energy losses, this can be treated by transferring loads between feeders, so that, the system is in a balanced case. This methodology can be performed by exploiting the switches that are included in the network. These switches are classified into two types. The first type, known as sectional switches. The sectional switches are always in $(\mathrm{ON})$ status in the normal operation of the system. While the other type known as tie switches. The tie switches are always in (OFF) status in steady state operation. Both types of switches use to enhance the performance of the system by select the proper status of switches to obtain the optimal path for loads flow this process known as NR (Hemdan et al., 2014; De Oliveira et al., 2014).

Shunt capacitors are vastly used in distribution system to reduce voltage deviation, minimize active power losses ncrease the feeder's capacity and inject reactive power to enhancement performance of the system. To

Corresponding Author: Ali Kadhem Hamzah, Department of Electrical Engineering, Technical College, Middle Technical University, Baghdad, Iraq 
obtain the most benefit possible, the installation of shunt capacitors must be by an optimal method at distribution systems. The optimal method meaning that is find the optimal solution for the problem of the numbers of the capacitors used the optimal location for installation within the system and the best size and type of shunt capacitors used within the system (Askarzadeh, 2016). There have been many researches on the subject about network reconfiguration and capacitor placement simultaneously used many algorithms. Sedighizadeh et al. (2014) used Improved Binary Particle Swarm Optimization (IBPSO) to mitigate the active power losses of (DS) and improve the voltage profile of system. The effeteness of the algorithm has been investigated and tested on two of IEEE standard system them 16-buses and 33-buses. Radhika Priyadarshini (Priyadarshini et al., 2014) used Genetic Algorithm (GA) as a tool to perform the optimal size and location for capacitors placement also to calculate the (NR) optimization, the (GA) tested on a realistic system with 77-buses and 33-buses IEEE Standard system. Montoya and Ramirez (2012) proposed two algorithms where he used the genetic algorithm to solve the problem of optimum size and location of the capacitors in addition to use a Minimum Spanning Tree (MST) algorithm to obtain the optimum path of loads (NR) to improve the performance of the (DS) both previous algorithms have been tested on 33-buses IEEE standard system and 69-buses IEEE Standard system. Esmaeili et al. (2014) proposed fuzzy harmony search algorithm as a tool to achieve several goals including obtain the optimal size and location for capacitor placement, determine the optimal path for loads, total cost reduction of capacitors installation and active power losses in addition enhancement the harmonic state of the system and realistic (DS) represented by 83-buses of Taiwan Power Company. Chang (2008) propose intelligence technique represented by Ant Colony Search (ACS) algorithm as a tool to obtain 3 the best solutions for (NR) problem, optimal size and location for capacitors bank for voltage profile improvement and reduce the losses of electrical energy. The proposed technique has been applied on two different of (DS).

The best way to evaluate the behavior and performance of any distribution system is by load flow analysis, Newton-Raphson, Fast-Decoupled and Gauss-Seidel, all of which failed to achieve convergence due to high/ratio, therefore, new method has been used for load flow analysis known as (Backward Sweep (BS) Forward Sweep (FS)) method.

Load flow analysis: The "Backward-Forward sweep" method use to load-flow study is an iterative technique in which two computational steps are performed at each iteration, it have two groups of matrixes, the first matrix for calculation the phase voltage, starting from substation and continuous in forward direction toward the last part of (DN) this matrix known as Forward Sweep Matrix (FSM) while the other matrix for computation load flow through the sections starting from last section and continuous in backward direction toward the main node this matrix known as Backward Sweep Matrix (BSM) (Rupa and Ganesh, 2014).

\section{MATERIALS AND METHODS}

Problem statement: The (NR) optimization is define as changing the topology of the network by select the optimal path of loads flow, the operation is done by changing the switches state (ON/OFF) with presence the capacitors bank which defined by calculating the optimal location, numbers, size and type of capacitors for installation at (DS) in such case, there are several objective functions. The major aim from applied mentioned previous techniques is to improve the performance of (DS) for both voltage dip reduction and minimize the active power losses of (DS) subject to operational constraints, e.g., standard community voltages:

$$
\left|V_{1 \text { limit }}^{\text {lower }}\right| \leq\left|V_{\text {limit }}\right| \leq\left|V_{\text {limit }}^{\text {upper }}\right|
$$

where, the $\left|v_{\text {limit }}^{\text {lower }}\right|$ and $\left|v_{\text {limit }}^{\text {upper }}\right|$ are the lowest and largest magnitude values of the allowed node voltage, improvement the deviation of thermal limit $\left(\left|I_{n}\right| \leq\left|I_{n \text { max, nek }}\right|\right.$. Where the $\left|I_{n}\right|$ and $\left|I_{n \text { max, nek }}\right|$ are the magnitude values of the current flows through branch and maximum current flows through the branch, the last of operational constraints is keeping the radial structure after applied (NR) technique. Figure 1 shows the single line diagram for Radial Feeder (RF) of (DS) (Abdelaziz et al., 2016).

From the Fig. 1, the real Power $\left(\mathrm{P}_{n}\right)$ and imaginary power $\left(Q_{n}\right)$ that flow through Section $(S)$ from node $(n)$ to node $(n+1)$ as given in Eq. 1 and 2 :

$$
\begin{aligned}
& P_{n}=P_{n+1}+R_{s} \times \frac{\left(P_{n+1}^{2}+Q_{n+1}^{2}\right)}{V^{2}{ }_{n+1}} \\
& Q_{n}=Q_{n+1}+X_{s} \times \frac{\left(P_{n+1}^{2}+Q_{n+1}^{2}\right)}{V_{n+1}^{2}}
\end{aligned}
$$

The mathematical expression for over all real and imaginary power for (DS) with or without applies and (BC) techniques that will assess the performance of system and 


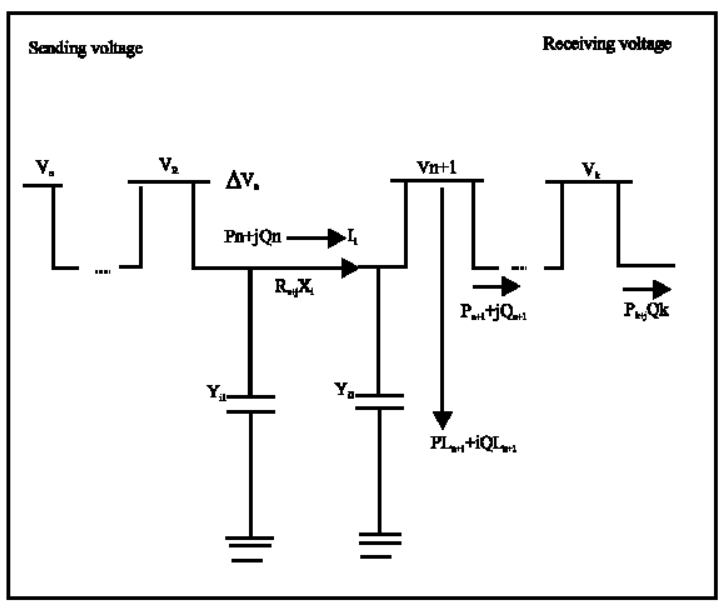

Fig. 1: Scematic diagram for single line RF

the change that occur through this mathematical expressions (Rao et al., 2013). The Overall Active Power Losses (OAPL):

$$
==\sum_{s=1}^{n-1} R_{s} \times \frac{\left(P_{n}^{2}+Q_{n}^{2}\right)}{V_{n}^{2}}
$$

The Overall Imaginary Power Losses (OIPL):

$$
==\sum_{s=1}^{\mathrm{n}-1} \mathrm{X}_{\mathrm{s}} \times \frac{\left(\mathrm{P}_{\mathrm{n}}^{2}+\mathrm{Q}_{\mathrm{n}}^{2}\right)}{\mathrm{V}_{\mathrm{n}}^{2}}
$$

The problem of losses minimization in system is formulated as:

$$
\min \sum_{s=1}^{n-1} R_{s} \times \frac{\left(P_{n}^{2}+Q_{n}^{2}\right)}{V_{n}^{2}}
$$

The voltage magnitude of the nodes can be calculated using the Kirchhoff Voltaic Act as given in Eq. 6 and 7 :

$$
\begin{gathered}
V_{n}=V_{n+1}+I_{s} \times\left(R_{s}+j X_{s}\right) \\
V_{n+1}=V_{k}+I_{s+1} \times\left(R_{s+1}+j X_{s+1}\right) \\
n=1,2,3, \ldots, K \\
s=1,2,3, \ldots, k-1
\end{gathered}
$$

The mathematical expression for voltage regulation for (DS) with or without applies (NR) and capacitors bank techniques that will assess the performance of system and the change that occur through this mathematical expression:

$$
\Delta \mathrm{V}_{\mathrm{n}}=\sum_{\mathrm{n}=1}^{\mathrm{k}} \frac{\mathrm{V}_{\mathrm{n}}-\mathrm{V}_{\mathrm{n}+1}}{\mathrm{~V}_{\mathrm{n}+1}}
$$

The problem of reduce voltage dip in system is formulated as:

$$
\min \sum_{n=1}^{k} \frac{V_{n}-V_{n+1}}{V_{n+1}}
$$

Equation 9 can simplify to:

$$
\min \sum_{n=1}^{k} \frac{V_{n}}{V_{n+1}}-1
$$

Software and algorithm steps: CYME was established in the late 19th century, a company specialized in software's to provide the best engineering solutions for all the problems facing the electrical power sector around the world and within a period of time CYME has become one of the leading companies in this area and was classified as a global supplier of engineering software in the field of electric power, offering consumers and engineering's, a complete solutions to help them meet their requirements in electric power field in practical manner and realistic in this research CYME Software ash been used as tool to run the (NR) and capacitors bank techniques in an optimum algorithm, this algorithm can be summarized in the following steps:

\section{Alghorithm 1; Software and steps:}

Step 1: Input all necessary data (e.g., loads data, lines data, ..., etc)

Step 2: Execute load allocation

Step 3: Execute load flow analysis (BS/FS) approaches to compute the bus voltage magnitude and active

power losses as so as all operational constraints must be check to verify if the system in its steady stat

Step 4: Assume that loads will growth relatively for a specified period (from 2018-2022)

Step 5: Repeat step 3

Step 6: Apply (NR) technique to improve network performance by transferring loads among feeders

Step 7: Repeat step 3

Step 8: In the case that the network reconfiguration technique did not achieve operational restrictions, go to next step, otherwise, move to step 11

Step 9: Apply (CP) technique to overcome of growing demand and achieve the operational restrictions

Step 10: Repeat step 3

Step 11: Display results and stop

Figure 2 shows the flowchart of adopted algorithm for (NR) and capacitors bank techniques simultaneously, taking into account Load Growth (LG).

System modeling: Figure 3 which represent the single line diagram for 69-bus of the radial distribution network that has 68 sections each one of them has a sectional 


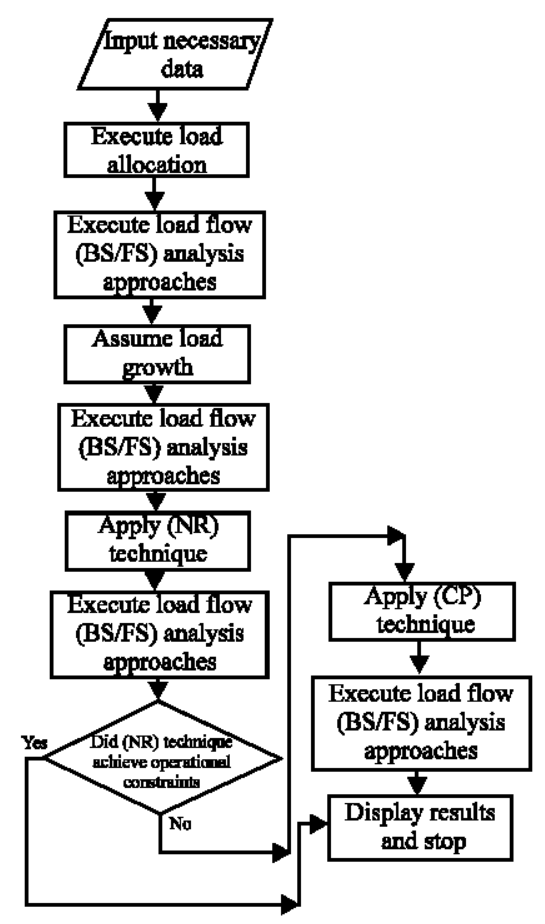

Fig. 2: Flow chart of adopted alghorithm for (NR)

switch normally closed, 5 tie switch which normally opened with system voltage $12.66 \mathrm{kV}$, a total maximum load 3600 as active power and 2690 as reactive power, the total losses $224.93 \mathrm{~kW}$. All data of system are illustrates by Savier and Das (2007).

Work assumptions: The base power of the adopted system $\mathrm{s}_{\mathrm{b}}=100 \mathrm{MVA}$, nominal voltage $\mathrm{v}_{\mathrm{b}}=12.66 \mathrm{kV}$ and the nominal frequency $\mathrm{f}=60 \mathrm{~Hz}$. All three phases of adopted system were in balanced with spot load in each nod and the voltage of slag bus is 1.0 p.u. Just one capacitor is permissible in each node (Rajaram et al., 2015).

\section{RESULTS AND DISCUSSION}

The adopted algorithms have been executed on 69-buses IEEE Standard (DS) using CYME Software, all obtained results have been arranged in tables and it was discussed in detail. Figure 3 shows the single-line diagram of adopted system when the power flow analysis has been applied where the red color indicates that the decline in voltage in those areas due to the growth of loads and increased demand for energy and caused the increase also to the emergence of areas suffer from the high level of loading and this is indicated by yellow, the minimum voltage was ( 0.87 p.u.) at bus 65 while the total

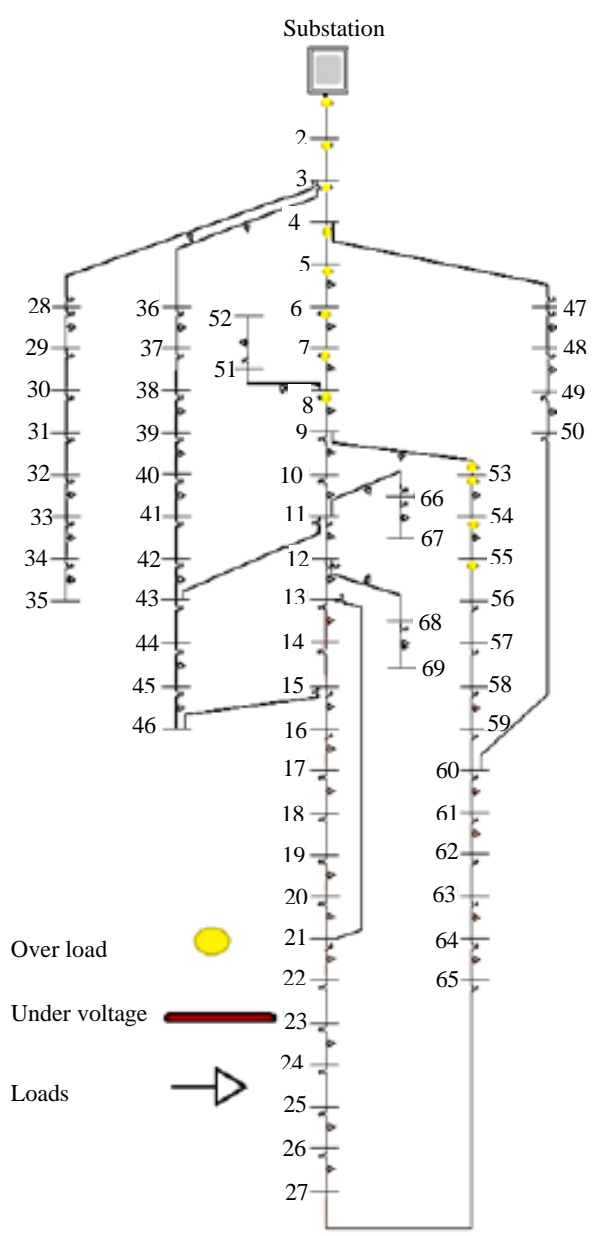

Fig. 3: Single line diagram for 69-bus system

of active power losses about $(465.4 \mathrm{~kW})$, this means that the system will suffer from a significant drop in the voltage and a significant increase in energy losses over the next 5 years with the imposition of a certain load growth rate which requires scientific planning to bring the system back to normal working condition (acceptable bus voltages and low active power loss) and this is through the application of the techniques adopted in this research. The effect of the above techniques is shown in Fig. 4, which shows the optimal location and type of capacitors, as well as optimal path the of load flow by select the optimal status of switches in the grid, resulting in the disappearance of colored areas in red (unacceptable voltages) and also reduce areas colored in yellow (over load), the minimum magnitude of bus voltage has been improved from (0.87-0.952) p.u. Also, the active power losses have been reduced from $(465.4-126.12 \mathrm{~kW})$, the Table 1 illustrates the effectiveness of adopted techniques by made comparison between summery load 
Table 1: Simulation results for both cases

\begin{tabular}{lll}
\hline Items & (LG), without improve tech. (LG) with improve tech. \\
\hline Active power losses & 456.4 & 126.12 \\
Min bus voltage (p.u.) & 0.87 & 0.952 \\
Opened switches & $69,70,71,72,73$ & $10,13,20,59,63$ \\
\hline
\end{tabular}

Table 2: Size and location of capacitors bank

\begin{tabular}{lcl}
\hline Size (MVAR/phase) & Location/section & Types \\
\hline 450 & 70 & Switched \\
450 & 72 & Switched \\
\hline
\end{tabular}

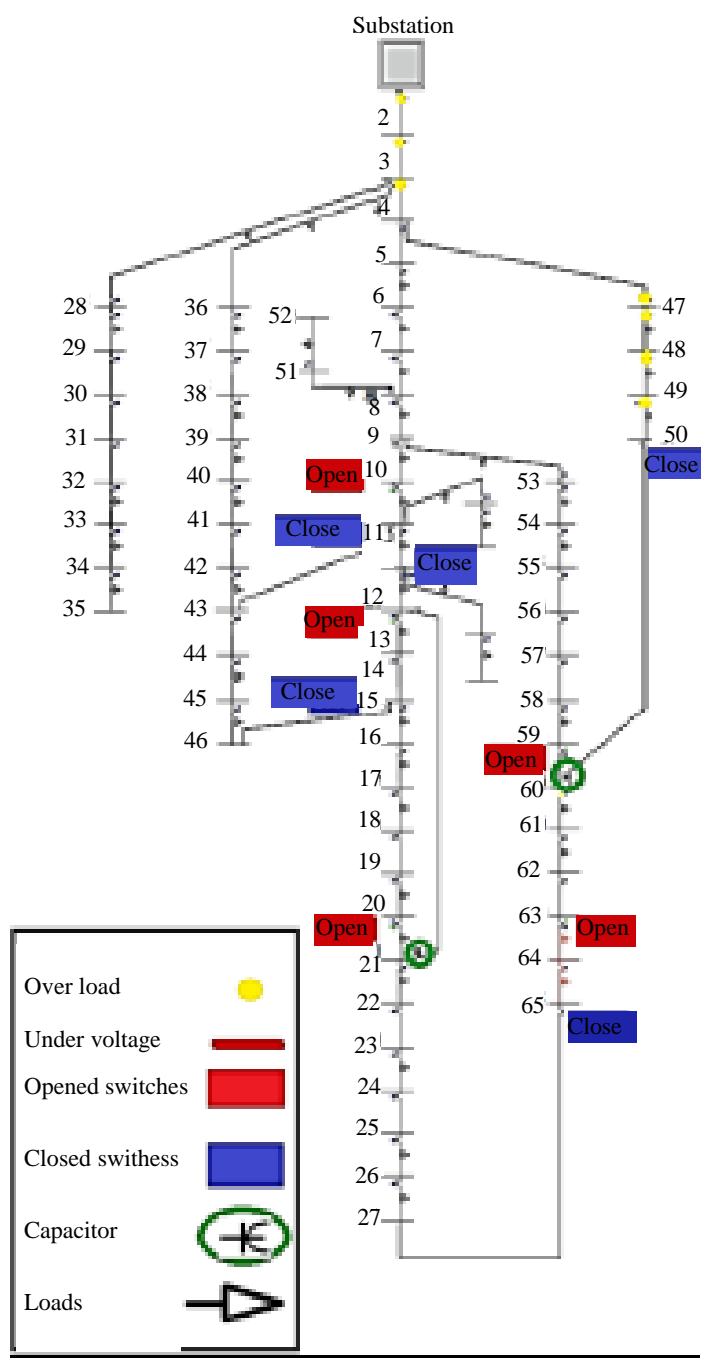

Fig. 4: Capacitors optimal location

flow reports, before and after applying optimization techniques, Fig. 5 shows the carves of voltages profile of system before and after applying improve techniques which shows the obvious effect of the techniques used to improve all electrical efforts of the buses while Fig. 6 shows the effect of application of

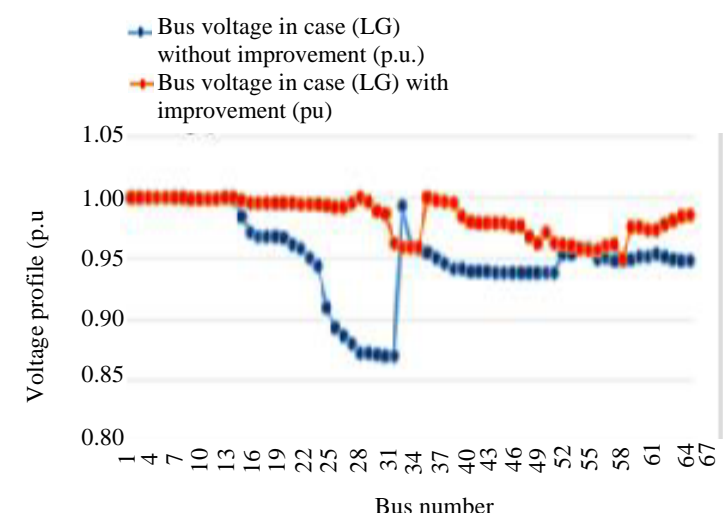

Fig. 5: Voltage profile of the system

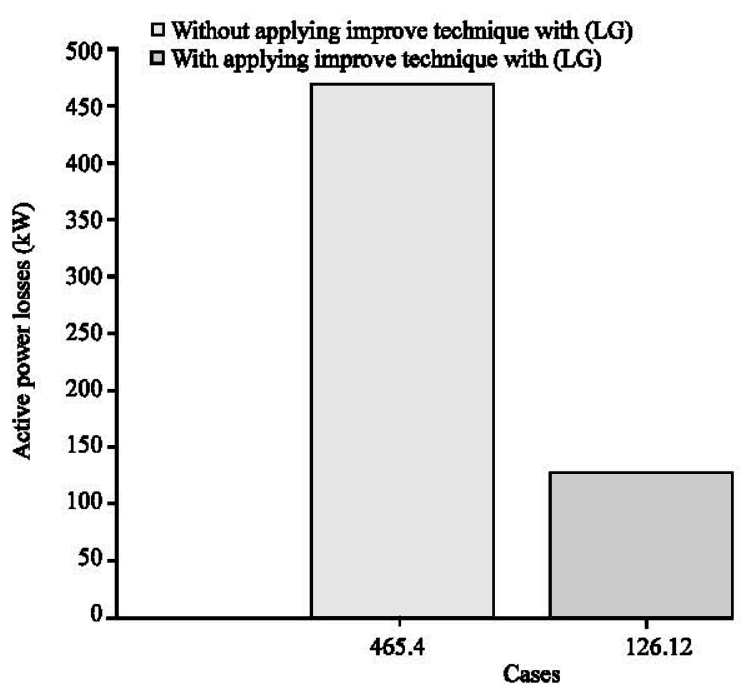

Fig. 6: Effects of application of techniques on active power losses

techniques on active power losses. Table 2 illustrates the results for load growth including active power losses and minimum bus voltage, opened switches shown in Table 1 while the capacitor size is shown in Table 2.

From the two tables it is clearly shown that the active power losses is reduced by about $72 \%$ which represent worthy reduction and at the same time, the improving in terminal voltage is reach about $8.6 \%$ from its value before improving technique. The size and location of bank capacitors per phase is shown with the best location in the distribution system under consideration.

\section{CONCLUSION}

In this research, the effect of two techniques (network redesign and capacitor placement) is tested 
simultaneously to ensure the quality of power processed for consumers with the imposition of the worst conditions of the distribution network (load growth) for a certain period of time in other words test the techniques mentioned earlier in the worst operational conditions of the system (a significant drop in voltages and very high losses in energy). The problem of location optimization, size, type and number of capacitor placement has been solved in addition to optimal flow of load using CYME program as a tool for the application of the a for ementioned techniques. The function of the network reshaping technique was determined to reduce the energy losses while the capacitor function was determined to reduce the voltage deviation. The techniques were implemented on IEEE Standard 69-bus system. The results were very satisfactory in terms of improving file voltages and reducing energy losses with operational presumed operating limitations of this research.

\section{REFERENCES}

Abdelaziz, A.Y., E.S. Ali and S.A. Elazim, 2016. Flower pollination algorithm and loss sensitivity factors for optimal sizing and placement of capacitors in radial distribution systems. Intl. J. Electr. Power Energy Syst., 78: 207-214.

Askarzadeh, A., 2016. Capacitor placement in distribution systems for power loss reduction and voltage improvement: A new methodology. IET. Gener. Trans. Distrib., 10: 3631-3638.

Badran, O., S. Mekhilef, H. Mokhlis and W. Dahalan, 2017. Optimal reconfiguration of distribution system connected with distributed generations: A review of different methodologies. Renewable Sustainable Energy Rev., 73: 854-867.

Chang, C.F., 2008. Reconfiguration and capacitor placement for loss reduction of distribution systems by ant colony search algorithm. IEEE. Trans. Power Syst., 23: 1747-1755.

De Oliveira, E.J., G.J. Rosseti, L.W. De Oliveira, F.V. Gomes and W. Peres, 2014. New algorithm for reconfiguration and operating procedures in electric distribution systems. Intl. J. Electr. Power Energy Syst., 57: 129-134.

Esmaeili, S., H.D. Dehnavi and F. Karimzadeh, 2014. Simultaneous reconfiguration and capacitor placement with harmonic consideration using fuzzy harmony search algorithm. Arabian J. Sci. Eng., 39: 3859-3871

Ganesh, S., 2014. Network reconfiguration of distribution system using artificial bee colony algorithm. WASET. Intl. J. Electr. Electron. Sci. Eng., 8: 1-7.
Hemdan, N.G., B. Deppe, M. Pielke, M. Kurrat and T. Schmedes et al., 2014. Optimal reconfiguration of radial MV networks with load profiles in the presence of renewable energy based decentralized generation. Electr. Power Syst. Res., 116: 355-366.

Kuzle, I., D. Bosnjak and H. Pandzic, 2009. Comparison of load growth prediction methods in distribution network planning. Proceedings of the 2009 20th International Conference and Exhibition on Electricity Distribution-Part 1, June 8-11, 2009, IET, Prague, Czech Republic, pp: 1-4.

Montoya, D.P. and J.M. Ramirez, 2012. Reconfiguration and optimal capacitor placement for losses reduction. Proceedings of the 2012 6th IEEE/PES International Conference on Transmission and Distribution: Latin America and Exposition (T\&D-LA), September 3-5, 2012, IEEE, Montevideo, Uruguay, ISBN:978-1-4673-2672-8, pp: 1-6.

Priyadarshini, R., R. Prakash and C.B. Shankaralingappa, 2014. Joint optimization for capacitor placement and network reconfiguration for loss reduction in distribution system. Proceedings of the 2014 IEEE International Conference on Power Electronics, Drives and Energy Systems (PEDES), December 16-19, 2014, IEEE, Mumbai, India, ISBN:978-1-4799-6372-0, pp: $1-6$.

Rajaram, R., K.S. Kumar and N. Rajasekar, 2015. Power system reconfiguration in a radial distribution network for reducing losses and to improve voltage profile using modified plant growth simulation algorithm with Distributed Generation (DG). Energy Rep., 1: 116-122.

Rao, R.S., K. Ravindra, K. Satish and S.V.L. Narasimham, 2013. Power loss minimization in distribution system using network reconfiguration in the presence of distributed generation. IEEE Trans. Power Syst., 28: 317-325.

Rupa, J.M. and S. Ganesh, 2014. Power flow analysis for radial distribution system using backward/forward sweep method. Intl. J. Electr. Comput. Electron. Commun. Eng., 8: 1540-1544.

Savier, J.S. and D. Das, 2007. Impact of network reconfiguration on loss allocation of radial distribution systems. IEEE. Trans. Power Delivery, 22: 2473-2480.

Sedighizadeh, M., M. Dakhem, M. Sarvi and H.H. Kordkheili, 2014. Optimal reconfiguration and capacitor placement for power loss reduction of distribution system using improved binary particle swarm optimization. Intl. J. Energy Environ. Eng., 5: 1-11. 